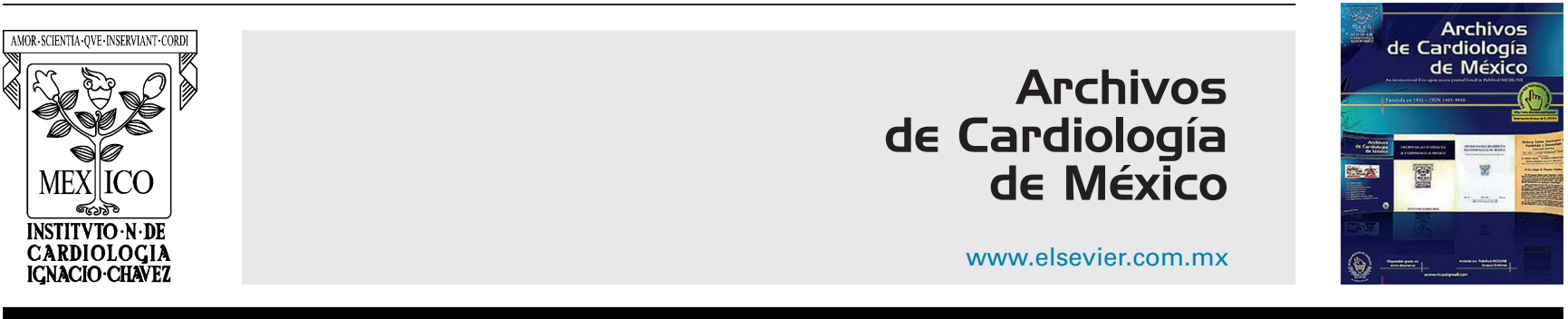

IMAGEN EN CARDIOLOGÍA

\title{
Cuerda auricular izquierda accesoria: causa infrecuente de insuficiencia mitral en niños
}

\section{Accessory left atrial chordae: an unusual cause of mitral regurgitation in children}

\author{
Daniel Hurtado-Sierraa,*, Óscar Fernández-Gómez ${ }^{a}$, Francisco Manrique-Rincón ${ }^{a}$, \\ Clara A. Vázquez-Antona ${ }^{\mathrm{b}}$ y Alfonso Buendía-Hernández ${ }^{\mathrm{c}}$ \\ a Servicio de Cardiología pediátrica, Instituto del Corazón de Bucaramanga, Colombia \\ b Departamento de Ecocardiografía pediátrica, Instituto Nacional de Cardiología Ignacio Chávez, Ciudad de México, México \\ c Departamento de Cardiología pediátrica, Instituto Nacional de Cardiología Ignacio Chávez, Ciudad de México, México
}

Recibido el 14 de septiembre de 2017; aceptado el 21 de noviembre de 2017

La presencia de cuerdas tendinosas accesorias de la válvula mitral son un hallazgo poco frecuente y resulta aún más raro la presencia de cuerdas tendinosas accesorias a nivel de la aurícula izquierda. Estas bandas de tejido accesorio habitualmente unen la cara auricular de la valva mitral anterior con el septum interauricular o el techo de la aurícula izquierda. Los casos reportados se han asociado a insuficiencia mitral importante por prolapso de la valva anterior generada por la tracción ejercida por la cuerda auricular izquierda accesoria. Usualmente no son diagnosticadas con el ecocardiograma y por el contrario son un hallazgo intraoperatorio.

Presentamos el caso de una paciente de 10 años que acude a nuestro centro por cuadro clínico de un año de evolución, caracterizado por deterioro progresivo de la clase funcional, asociado a ortopnea y episodios sincopales recurrentes. En el examen físico se encontró el precordio hiperdinámico, con choque de la punta desplazado hacia abajo y a la izquierda, asociado a soplo holosistólico a nivel de ápex, irradiado hacia la axila. El ecocardiograma transtorácico evidenció regurgitación mitral severa con prolapso de la valva anterior, así como una banda lineal anormal al interior de la aurícula izquierda, uniendo la valva anterior de la válvula mitral con el techo de la aurícula izquierda (fig. 1). La experiencia quirúrgica en esta cardiopatía es extremadamente limitada y con frecuencia requiere de excisión de la cuerda tendinosa anómala, plastia de la valva anterior y anuloplastia mitral posterior. Este constituye el segundo caso reportado en la edad pediátrica $^{1-4}$.

\footnotetext{
* Autor para correspondencia. Cra. 28 \# 40-11, C.P. 680003, Bucaramanga, Colombia. Teléfono: (+57) (7) 6329291, Extensión: 158 Fax: (+57) (7) 6329200.

Correo electrónico: meddani@hotmail.com (D. Hurtado-Sierra).
} 

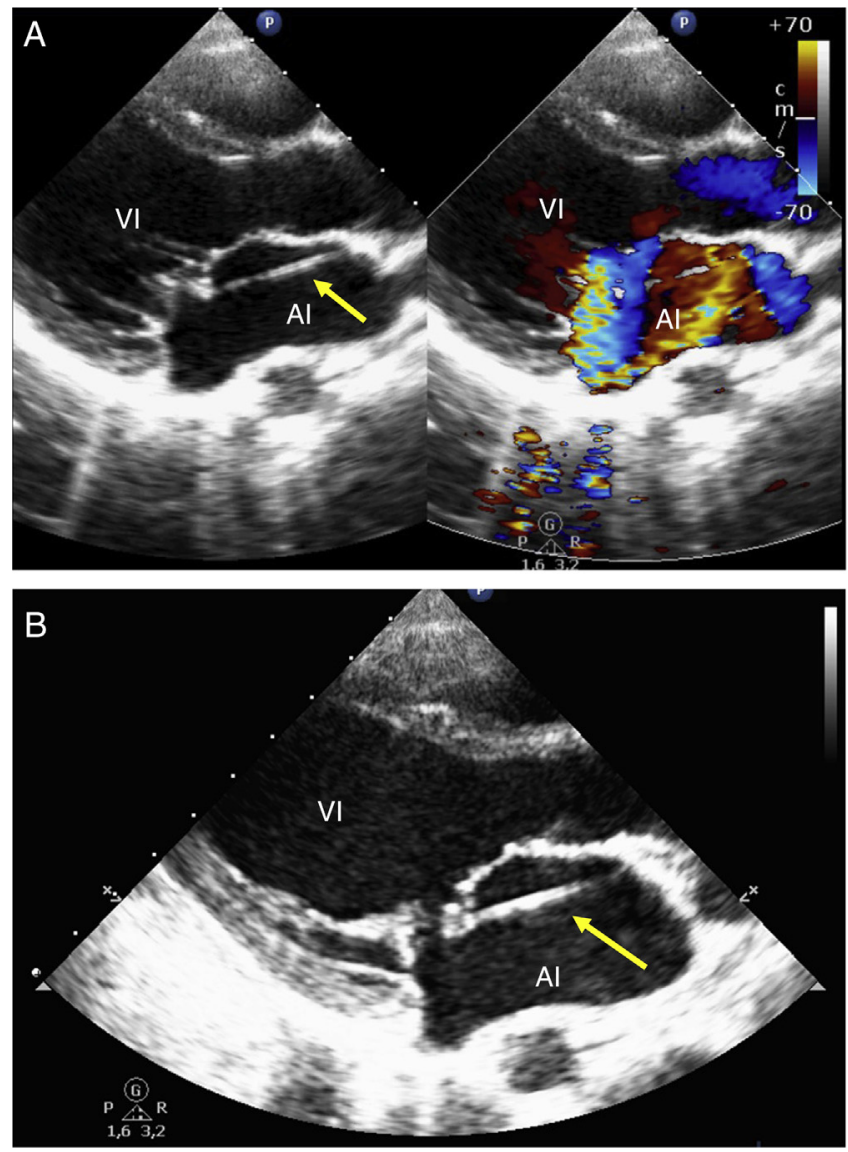

Figura 1 Ecocardiograma transtorácico. A) En proyección eje largo paraesternal izquierdo se muestra en 2D y Doppler color la presencia de una banda lineal anormal al interior de la aurícula izquierda (flecha amarilla), así como el jet de regurgitación excéntrico de la insuficiencia severa de la válvula mitral. B) Acercamiento de la válvula mitral que demuestra el prolapso de la valva anterior secundaria a la tracción ejercida por la cuerda auricular izquierda accesoria. El color de esta figura solo puede apareciarse en la versión electrónica del artículo.

\section{Financiación}

No se recibió patrocinio de ningún tipo para llevar a cabo este artículo.

\section{Conflicto de intereses}

Los autores declaran no tener ningún conflicto de intereses.

\section{Bibliografía}

1. Taqatqa A, Bokowski J, Polimenakos A. Congenital anomalous chordae tendinae of the mitral valve: an unusual presentation of mitral insufficiency in children. J Card Surg. 2010;25:584-5.

2. Sherif H, Banbury M. Accessory left atrial chordae: an unusual cause of mitral valve insufficiency. J Thorac Cardiovasc Surg. 2010;139:e3-4.

3. Taglieri C, Botta L, Roghi A, et al. Unusual insertion of a mitral chord causing severe valve regurgitation. Eur J Cardiothorac Surg. 2010;38:387.

4. Aksu H, Uslu N, Aslan M, et al. Mitral insufficiency caused by left atrial chordae. Echocardiography. 2012;29:E87-90. 